\title{
RETRATO DA ANTROPÓLOGA QUANDO JOVEM: SIMONI GUEDES - DOS ANOS DE FORMAÇÃO A SUBÚRBIO, CELEIRO DE CRAQUES
}

\author{
Bernardo Borges Buarque de Hollanda ${ }^{1}$
}

${ }^{1}$ Escola de Ciências Sociais, Centro de Pesquisa e Documentação de História Contemporânea do Brasil, Fundação Getúlio Vargas (FGV/CPDOC),

Rio de Janeiro, RJ, Brasil

\section{Introdução}

Em três-por-quatro, tirado em preto-\&-branco, o retrato da antropóloga chama a atenção logo na abertura de Universo do futebol. O livro, como se sabe, data de 1982 e foi publicado pela esmerada Edições Pinakotheke, uma editora do ramo de artes, em coletânea organizada por Roberto DaMatta. Conforme também sobejamente sabido, a obra é considerada por muitos o marco zero dos estudos futebolísticos em Ciências Sociais no Brasil (Damo 2002; Mascarenhas 2014; Gastaldo 2002).

Diferente das imagens mais espontâneas e sorridentes dos três outros colaboradores do livro, na mesma página de apresentação dos autores - DaMatta, Luiz Felipe Baêta Neves e Arno Vogel -, a foto de Simoni destaca-se pela seriedade da pose. Ao mostrar o rosto em posição frontal, seu olhar fixa-se rente à câmera, numa silhueta séria, que avulta pela simetria entre olhos, nariz e boca. Os cabelos escuros e lisos, ainda que levemente ondulados, contornam a fronte e distendem-se até a altura dos ombros, onde encontram uma blusa aberta, recortada em forma de V.

A fotografia, de início dos anos 1980, é provavelmente a primeira aparição pública da antropóloga na comunidade científica brasileira. Em 1982, contando 33 anos de idade, Simoni Lahud Guedes tem seus créditos assim apresentados junto à imagem: 
Mestre em Antropologia Social pelo Programa de Pós-Graduação em Antropologia Social do Museu Nacional na Universidade Federal do Rio de Janeiro, onde escreveu uma tese sobre o futebol brasileiro em seus aspectos sociológicos. É professora de antropologia social nas Universidades Federal Fluminense e Santa Úrsula.

Entre as inúmeras possibilidades de abordagem da vasta obra de Simoni, que se dilata por mais de quatro décadas de produção ininterrupta, escolhemos para este artigo de homenagem tratar de forma panorâmica das origens familiares e da trajetória juvenil, dos anos de formação e dos primeiros momentos da produção intelectual da autora. A menor familiaridade das gerações que estabeleceram contato com Simoni dos anos 1990 e 2000 em diante, como em nosso caso, trouxe-nos esse desafio de perfilar seu percurso e de acompanhar os seus primeiros escritos.

Cientes das limitações decorrentes das inúmeras lacunas de informação sobre a "jovem" Simoni - ou do reconhecimento da necessidade de uma pesquisa de maior fôlego que ouvisse um maior número de testemunhos de seus contemporâneos, o que logramos fazer aqui apenas parcialmente, conforme explicaremos a seguir -, entendemos ainda assim que esta será uma forma adequada de contribuirmos para a compreensão dos destinos da obra da Simoni "madura".

Essa, por assim dizer, segunda fase da trajetória de Simoni é marcada pela vinculação longeva como professora e pesquisadora do Departamento de Antropologia da Universidade Federal Fluminense, em especial do seu Programa de Pós-graduação. Por meio dele, Guedes formou gerações de cientistas sociais e antropólogos, participou de modo regular, para não dizer "militante", dos grupos de trabalho sobre esportes na ABA e na RAM.

Simoni estabeleceu ainda redes internacionais de pesquisa, notadamente com a Argentina e sua Universidade de Buenos Aires (UBA), onde fez seu pós-doutorado, e também com Portugal e sua Universidade Nova de Lisboa. Nessas instituições estrangeiras, manteve profícua interlocução com os pesquisadores Pablo Alabarces e João Sedas Nunes, respectivamente. Ademais, Simoni fomentou o convívio interinstitucional com historiadores, sociólogos e comunicólogos na condução do Nepess - Núcleo de Estudos em Esporte e Sociedade -, grupo de pesquisa da UFF, existente desde 2006.

Cremos que a breve reconstituição deste artigo ensejará pistas para melhor avaliar seu legado antropológico no campo científico das práticas e representações esportivas a partir dos anos 1990. Para tanto, o texto está subdividido em três partes. A primeira trata de apontamentos de biografia e da ambiência universitária da graduação de Simoni em Ciências Sociais, entre o final da década de 1960 e início dos anos 1970. 
A segunda parte versa sobre a entrada na pós-graduação do Museu Nacional e a feitura de sua "tese" de mestrado - como então se chamava em Antropologia Social, sob orientação de Luís de Castro Faria (1913-2004), intitulada O futebol brasileiro: instituição zero, defendida em 1977 e nunca publicada em livro.

A terceira e última parte examina a sua primeira publicação a tematizar o futebol, o capítulo "Subúrbio: celeiro de craques", que vem a lume no livro "fundador", organizado por um de seus mais influentes mestres, Roberto DaMatta, em princípios do decênio de 1980.

Antes de iniciar, uma breve nota metodológica: para que as informações biográficas fossem possíveis, foi imprescindível contar com a colaboração prestimosa da filha de Simoni, Mylene Guedes, que esclareceu, contextualizou e aportou diversas passagens da trajetória de vida de sua mãe. Parte da história do curso de Ciências Sociais da Universidade Federal Fluminense, onde Simoni se formou entre os anos 1960 e 1970, foi-nos compartilhada por uma contemporânea da turma de graduação e grande amiga ao longo da vida, Anamaria Wagner, que concedeu um rico relato do período e da colega.

Conversamos ainda com as professoras Marieta de Moraes Ferreira (UFRJ), Helena Bomeny (UERJ) e Lúcia Lippi (FGV), ex-alunas e ex-professoras da instituição naqueles anos, que trouxeram importantes testemunhos de época.

Antes de iniciar, cumpre assinalar que a motivação para este artigohomenagem é decorrência da influência da professora em minha formação. A leitura de seus escritos durante a pós-graduação e a aprendizagem em bancas, seminários e encontros acadêmicos motivaram o aprofundamento dessa faceta da autora, relativamente menos conhecida pelos que com ela conviveram, pelos que apenas tinham ciência desse percurso com base em relatos orais, ou ainda pelos que acederam ao seu memorial de concurso para professora titular em 2015. Acentuo igualmente a convivência com a professora nas reuniões do Nepess (Núcleo de Estudos e Pesquisas sobre Esporte e Sociedade), na UFF, criado em 2006 e do qual fui um dos seus colegas. ${ }^{1}$

\section{Bosquejos biográficos: ambiência de uma formação}

Esclarecimento preliminar: o título desta seção emprega o adjetivo da palavra biografia em sentido livre, como licença poética, pois, a rigor sua utilização no sentido pleno do termo necessitaria de aprofundamento 
teórico, a começar por Pierre Bourdieu no ensaio "A ilusão biográfica" (2006), referência muito apreciada por Simoni. Nela o sociólogo francês tenciona descontruir a acepção jornalística e de senso-comum, segundo a qual as trajetórias são narradas retrospectivamente de forma linear e coerente, como se o biografado tivesse um sentido e um destino traçados de forma prévia ou teleológica. Segundo a própria Simoni, é necessário "não sucumbir à tentação de dar sentido ao que é, muitas vezes, caótico, casual e desordenado" (Guedes 2017:340).

Feita a advertência, cumpre dizer que, originária de família de imigrantes libaneses, Simoni Lahud Guedes nasceu em 1949, no interior do Espírito Santo. Enquanto o pai - José Antônio Lahud - nascera no Líbano e migrara por volta dos 20 anos de idade para o Brasil, sua avó materna vem grávida para o país, onde nasce a mãe: Badiah Chicrala Lahud.

Depois de se conhecerem no município fluminense de Santo Antônio de Pádua, ambos viveram em São José do Calçado, cidadezinha capixaba de destino dos pais, onde Simoni vem a nascer. A região faz fronteira com o estado Rio de Janeiro e sofre a influência da cidade de Campos, no norte fluminense. Liga-se ao Rio via Bom Jesus do Norte e, através de uma ponte, a Bom Jesus do Itabapoana. A família de comerciantes tem um armarinho no centro da cidade.

Simoni é a caçula temporã. Tem mais seis irmãos, um deles 20 anos mais velho que ela. Conta-se que os pais não tinham planos de ter mais filhos, mas Simoni e Tarcísio nascem após o falecimento de um dos irmãos, o Chicralinha. O pai de Simoni falece quando ela tinha apenas 2 anos de idade. A perda paterna precoce faz a caçula vincular-se afetivamente a um de seus irmãos mais velhos, Antônio. Em cidade que ainda desconhecia escolas particulares, Simoni faz o primário no Grupo Escolar Manoel Franco e o ginásio no Colégio de Calçado, ambos, portanto, no ensino público local.

Em 1964, outro irmão, Tarcísio, decide mudar-se para a cidade de Niterói, no Rio, a fim de se preparar para o dificílimo vestibular de Medicina. Então com 15 anos, Simoni acompanha-o na mudança, ao lado de Antônio e da mãe, conhecida entre os da casa como Dona Bela. A família desfaz-se do estabelecimento comercial em Calçados e, enquanto uma parte do núcleo familiar vai para o Rio, a outra permanece no Espírito Santo, estabelecendo-se em cidades como a capital Vitória e Guarapari.

Breve parêntese: não cabe nos limites deste artigo o desenvolvimento da temática da imigração libanesa ao Brasil, desenvolvido entre outros por Mintaha Campos (1987). De todo modo, segundo conversas entretidas com Simoni Guedes, o historiador Luiz Burlamaqui assinala o destaque conferido pela autora à reconversão profissional da família de imigrantes 
em sua sucessão geracional. Muito marcada pela atuação no comércio, parte considerável das famílias, no entanto, investia na formação escolar de seus filhos, como no caso de Simoni. Neste sentido, destaquem-se exemplos de diferentes gerações intelectuais descendentes de sírio-libaneses, como o editor-livreiro Jorge Zahar, o historiador Sidney Chalhoub e o sociólogo Ronaldo Helal.

De volta à narrativa: adolescente, ótima aluna, Simoni cursa e se forma na escola normal do Colégio São Vicente de Paula, em Icaraí. Neste estabelecimento de ensino, Simoni cursa os dois primeiros anos do segundo grau - como se chamava à época o Ensino Médio. O terceiro ano é cursado no Instituto de Educação Ismael Coutinho, onde vem a ter aulas de sociologia. Através de uma amiga da escola, Maria Helena, vem a conhecer Milton, irmão da colega. Milton seria namorado, noivo e futuro marido, com quem se casa em julho de 1971, aos 22 anos de idade. O companheiro é nove anos mais velho que Simoni e teriam uma única filha, Mylene, que nasce em 1976. O casal separa-se no ano de 2000, após quase trinta anos de casamento.

Depois de fazer cursinho preparatório em setembro de 1967, Simoni ingressou na graduação de Ciências Sociais na UFF no ano de 1968, conturbado não apenas no Brasil como em boa parte do mundo. Tinha muitas dúvidas pela opção profissional e as Ciências Sociais lhe pareceram abertas o suficiente para amadurecer o que queria fazer na carreira ao longo da universidade. Segundo o relato de sua filha e de sua contemporânea de curso, Anamaria Wagner, era uma estudante dedicada e teve um excelente desempenho no vestibular.

À época, havia duas fases no processo seletivo: a primeira, objetiva, com questões de múltipla escolha, e a segunda, dissertativa, com perguntas vinculadas a uma vasta bibliografia de autores da sociologia e da antropologia brasileiras, que iam de Gilberto Freyre a Oliveira Vianna, chegando até a Guerreiro Ramos. A prova qualitativa era difícil e fazia-se necessário dominar uma lista de dez livros, que tematizavam as formas de poder no Brasil. Após passar pela primeira fase, a candidata gabarita na segunda fase e alcança o primeiro lugar em Ciências Sociais daquele ano.

A entrada no ensino superior e a escolha do curso de Ciências Sociais - na quarta turma da UFF, universidade fundada em 1960, com a criação do estado da Guanabara e seu desmembramento do estado do Rio (Corte \& Martins 2010) - deram-se por seu interesse mais amplo pelas Humanidades, sem que tivesse maiores informações prévias da atividade profissional e dos conteúdos de Antropologia, Sociologia e Ciência Política.

No entanto, desde o início da faculdade surpreende-se e vai-se afeiçoar pela área de Antropologia, disciplina sobre a qual tinha até então ideia vaga, tendo ouvido falar do antropólogo Darcy Ribeiro e dos seus 
estudos indígenas. Num período em que a universidade passava pela introdução do sistema de créditos para se formar, Simoni cursará nada menos que 15 cadeiras voltadas à teoria e à metodologia antropológicas. Isto era proporcionado, mesmo com a UFF tendo um departamento de antropologia pequeno, por apenas quatro professores: Luís de Castro Faria, Wagner Neves Rocha, Lúcia Câmara e Maria Maia de Oliveira Beriel.

Inteligente, Simoni já nessa época lê com afinco Bronislaw Malinowski, Ruth Benedict e Margaret Mead, aos quais se seguem Edmund Leach, Victor Turner, Mary Douglas, Marshall Sahlins, entre outros expoentes da antropologia. A despeito da enorme dificuldade de acesso à bibliografia, a disciplina lhe descortina um horizonte novo, uma forma insuspeitada de olhar o contexto social, encantando-se com o desafio de textos que não traziam respostas prontas sobre o mundo à sua volta. Identifica-se, numa palavra, com o que Roberto Cardoso de Oliveira chama de disciplina "poliparadigmática" (1998).

A Universidade Federal Fluminense, onde viria a lecionar durante toda a vida, e nela se tornar professora titular no ano de 2015, foi a instituição em que se graduou, primeiro no bacharelado em Ciências Sociais, depois na licenciatura plena em Educação. A antiga capital do estado do Rio de Janeiro foi, pois, a cidade onde estudou, lecionou e residiu da adolescência em diante. Além da vida universitária, o curso normal e a licenciatura permitiram-lhe lecionar no Ensino Fundamental (o ginásio) e no Ensino Médio (o então segundo grau) desde 1968.

Com matrícula no Estado, onde veio a se aposentar, foi professora de História no Instituto de Educação Professor Ismael Coutinho (Ipic) e no Colégio Estadual Machado de Assis, nos bairros niteroienses de São Domingos e do Fonseca. Enquanto cursava durante o dia o mestrado no Museu Nacional, no bairro de São Cristóvão no Rio, lecionava nas escolas de Niterói no período noturno, a fim de conciliar com suas pesquisas e leituras.

A graduação foi feita em quatro anos, com a obtenção do título de bacharel em 1971. Simoni continua na UFF por ainda mais dois anos, até 1973, para concluir a licenciatura, habilitação, como dito acima, que lhe seria útil ao longo da vida, sendo conhecida por centenas, provavelmente milhares de alunos, como uma excelente professora. Docente dotada de voz altissonante, foi sempre extrovertida e tinha uma extrema facilidade de comunicar-se com seus alunos e com grandes audiências. Tinha um jeito despachado e informal de ser, era direta, sem meias palavras. Ao mesmo tempo, dispensava grande atenção, quase maternal, a seus discentes e orientandos. Apoiava-os, incentivava-os e preocupava-se com seu encaminhamento profissional. 
Em termos históricos, a formação universitária em nível de graduação de Simoni dá-se na esteira do AI-5, durante o período mais repressor e cruel do regime ditatorial (1964-1985), em meio aos chamados "anos de chumbo", quando a ditadura, nas palavras do jornalista Elio Gaspari, tornou-se "escancarada". Ainda de acordo com o relato da filha Mylene e da amiga Anamaria, a jovem universitária Simoni não se enquadrava nos estereótipos da época, muito presentes nas Ciências Sociais, no tocante ao engajamento político ou à rebeldia comportamental da contracultura.

Como se sabe, foi contemporânea da geração que, por um lado, aderiu à luta armada no interior do país - havia alunos do MR-8 e outras organizações clandestinas em sua turma - e, por outro, no plano existencial e nas grandes cidades, assistiu ao esfacelamento dos projetos coletivos e utópicos de transformação social no Brasil e na América Latina. As décadas de 1960 e 1970 presenciaram o contexto bipolar da Guerra Fria e muitos optaram por refugiar-se no hedonismo, na rebeldia geracional, nas experimentações sexuais e nas transgressões das drogas.

Nas Ciências Sociais, os estudantes de Sociologia e Ciência Política eram os mais mobilizados, ao passo que os de Antropologia eram vistos como menos politizados. Não obstante, recorda-se Anamaria Wagner, na UFF os cursos com alunos mais engajados não se encontravam nem na História nem nas Ciências Sociais, mas em Serviço Social e em Engenharia. Este último curso, inclusive, liderava o Diretório Central dos Estudantes (DCE) à época, sendo bastante ativo.

Outro dado importante de ambientação da sua trajetória na universidade, entre 1968 e 1973, diz respeito à Copa de 1970, realizada no México, afamada tanto pela conquista do tricampeonato quanto pelo ofuscamento que a comemoração do título produziu nas práticas de tortura e na infração sistemática dos direitos humanos contra os opositores cometidos por policiais e militares. É sabida a polarização produzida pelo Mundial no campo da esquerda e o impacto negativo que teve na penetração do futebol como objeto de estudos ao longo dos anos 1970 (Ramos 1984; Sebreli 1998).

Ainda segundo sua filha, o futebol sempre foi, desde a infância no Espírito Santo, um assunto presente e de interesse familiar. De acordo com Anamaria, Simoni já era uma arrebatada torcedora na época da faculdade. Assistia de casa, ainda não ia ao Maracanã. Isto passa a ser mais comum nos anos 1980, com seu fervor de torcedora do Clube de Regatas do Flamengo, como, anos mais tarde, na memória viva dos que a conheceram, ela ficou marcada. Não obstante, quando se tratava de pesquisa e reflexão acadêmica, sabia-se distanciar do clubismo e era bastante rigorosa com seus orientandos quanto a isso, muitas vezes dissuadindo-os de estudar clubes para os quais torciam. 
Durante a graduação, vivia-se o período político chefiado por Médici, repleto de crueldades e repressão. O sistema repressivo abateu-se com mais intensidade sobre inúmeros campi e recrudesceu em diversos centros universitários do país, refúgio de parcelas expressivas de uma juventude de classe média que fazia oposição ao regime militar, cujo cotidiano é examinado em estudo notável pela cientista política Maria Hermínia Tavares de Almeida (1998). Como é de se supor, os cursos de Sociologia e afins estiveram entre os mais atingidos e reprimidos na época.

Nas lembranças constantes do memorial de titularidade, Simoni recorda-se dessa maneira:

No primeiro ano da minha turma no curso, convivemos com o agravamento da repressão militar que culminaria com o AI-5, em 13 de dezembro de 1968. Vivíamos cotidianamente o terror na sala de aula, com alguns colegas, da nossa turma ou das outras, desaparecendo de um dia para o outro, sem que tivéssemos qualquer notícia. Além disso, nosso professor de sociologia era militar e nos ensinava uma sociologia impressionantemente insípida. Falávamos baixo sobre a situação política e apenas com algumas pessoas que conhecíamos bem, pois o clima predominante era de suspeição generalizada, já que tínhamos notícia de que o regime infiltrara agentes nas salas de aula para denunciar os "comunistas". Algumas pessoas, corretamente ou não, foram alvo de suspeitas que as isolavam. Esse clima se estendia a muitos outros espaços sociais (2019:348).

A década de 1960 tinha sido marcada pelo debate em torno da Reforma Universitária, que afinal foi implantada pelo Ministério da Educação (MEC) em novembro de 1968, mesmo ano em que Simoni ingressa na UFF. A Reforma tencionava a ampliação de vagas no ensino superior, em decorrência do aumento da demanda e do crescimento demográfico da população brasileira, notadamente dos jovens. A mudança ocasionou o fim das turmas e a fragmentação dos estudantes, por meio do sistema de créditos e da formação departamental. Ademais, um dos efeitos da LDB de 1968 durante a ditadura foi a expansão das faculdades particulares, o que se materializou no decurso da década de 1970.

Quanto à repressão, a UFF teve algumas particularidades no Rio de Janeiro, se comparada aos cursos de Sociologia e Política da PUC-Rio e de Ciências Sociais da UFRJ - nova nomenclatura da antiga Universidade do Brasil, que muda em 1967, com a Reforma Universitária. Estas duas - PUC e UFRJ - ficavam na capital do então Estado da Guanabara (1960-1975), enquanto a UFF na capital do Estado do Rio de Janeiro. ${ }^{2}$

Lembre-se que a ligação da cidade do Rio com Niterói até 1974, quando da inauguração da pujante ponte de 13 quilômetros de extensão, um dos 
feitos faraônicos da ditadura, fazia-se via de regra pelas barcas, meio de transporte característico das cidades e ilhas que pontilhavam a Baía da Guanabara. No âmbito político, segundo o testemunho da então estudante de História da UFF, Marieta de Moraes Ferreira, hoje professora titular da UFRJ:

A UFF a partir de 1968 se constituiu em um espaço mais liberado. No IFCS, era a repressão total. Na UFF, os cursos tinham muito uma orientação marxista, mas a repressão não era muito visível. De toda forma, como era universidade pública, pedia atestado ideológico para contratar. Mas quem já estava no quadro tinha bastante liberdade nas suas aulas.

O campus do Gragoatá, no sub-bairro da Cantareira, ainda não existia. Quando Simoni entrou na universidade, as aulas dos cursos de Humanas situavam-se em Icaraí, junto ao prédio da Reitoria, no seu terceiro andar. Lá foi a primeira sede do curso de Ciências Sociais, criado na UFF em 1964. Seis anos mais tarde, em 1970, as aulas mudam para a Rua Lara Vilela, no prédio do Colégio Bittencourt Silva, no bairro niteroiense do Ingá. Anos depois, em 1977, quando Simoni já estava não só formada, como também havia conquistado o título de mestre em Antropologia e começava a lecionar na própria UFF, as Ciências Sociais encontravam-se em prédio novo, no campus do Valonguinho, no centro de Niterói. Seria apenas nos anos 1990 que o Bloco O do Gragoatá abrigaria os cursos de História e Ciências Sociais, no prédio em que a maioria dos contemporâneos de nossa geração que conheceram Simoni lembra-se dela.

É difícil precisar a grade curricular e as disciplinas cursadas na graduação, bem como identificar quais foram seus professores, mas, graças à Anamaria Wagner, conseguimos levantar algumas informações oportunas. Faziam parte do corpo docente de então, entre outros: Ronaldo Coutinho, na Sociologia; José Nilo Tavares, na Ciência Política; Maria Antonieta Leopoldi, na História; Rosilene Alvim, na Antropologia; Santo Conterato, na disciplina de Métodos e Técnicas de Pesquisa; José Jeremias de Oliveira Filho, na matéria de Metodologia das Ciências Sociais, além de cursos de Economia e Estatística, cujos professores eram recrutados de seus respectivos departamentos.

A própria Simoni, em seu memorial para o concurso para professora titular da UFF, assinala a professora Lúcia Câmara e seus "ótimos cursos" de Cultura e Personalidade (Guedes 2017:347) Entre os colegas de turma, Simoni lembra de Laurita dos Santos, de Almir Abreu e da própria Ana Wagner. Entre contemporâneos de geração na faculdade, destacam-se Eliane Cantarino, do curso de História; Delma Pessanha, estudante de Serviço Social, e Roberto Kant de Lima, um pouco mais velho, formado em Direito 
e estudante de Ciências Sociais. Os três se tornariam amigos e parceiros de vida universitária no decorrer das décadas, sendo que Eliane viria a ser colega de mestrado de Simoni e Kant, parceiro do Nufep (Núcleo Fluminense de Estudos e Pesquisas).

Entre todos os professores, encontramos as referências mais elogiosas, expressamente "decisivas", de Simoni ao antropólogo Wagner Neves da Rocha, aluno de DaMatta e estudioso de religião. Considerava-o um ótimo professor, entusiasmado pela Escola Sociológica Francesa e assinante da revista L'Année Sociologique. Foi Wagner quem a introduziu à obra As formas elementares da vida religiosa (1912), de Durkheim, na sala de aula.

Esse docente tinha ainda o hábito de levar suas turmas ao cinema e, em seguida, continuavam em sua casa o encontro para debater o filme. Anamaria Wagner, por exemplo, recorda-se em 1969 da ida à sala de cinema em Icaraí com os colegas da classe para assistir a 2001 - uma Odisseia no espaço, de Stanley Kubrick, na companhia do professor. Nesse período é criado o Cine Arte UFF, sob a liderança do cineasta Nelson Pereira dos Santos, e Simoni tem a oportunidade de assistir a sessões com a presença de expoentes do cinema brasileiro de então.

Um dos grandes destaques da graduação é Luís de Castro Faria, influente professor da UFF durante a graduação, que a introduz, entre outras correntes, nos chamados "estudos de comunidade". A influência de Castro Faria, "com seu cachimbo, sua sapiência e impaciência" (Guedes 2017:347), timbrará também a pós-graduação do Museu Nacional, instituição para onde Simoni se dirige em 1972, com a orientação deste veterano e importante antropólogo carioca.

\section{Museu Nacional, instituição-zero: a constelação do futebol}

Simoni prestou o processo seletivo para o mestrado em Antropologia Social no Museu Nacional no segundo semestre de 1971, enquanto ainda terminava sua graduação. Em entrevista para o portal Ludopédio, explica como eram diferentes os critérios de seleção de candidatos à época:

Eu entrei no mestrado em 1972. Na verdade, isso é uma coisa que eu me lembro bem. O sistema de seleção do Museu Nacional, na época, era muito interessante. Você ia lá, você pegava uma série de temas de pesquisa. E você tinha uma semana para escolher um. Você escolhia um daqueles temas e tinha que produzir alguma coisa sobre aquilo, um material de campo, mínimo que fosse, e juntar uma bibliografia, e na semana seguinte você ia para lá. Você podia levar notas, 
anotações, mas não podia levar pronto; e você redigia lá a sua prova, com base naquela experiência. Eu me lembro que tinha vários temas. E tinha um que eu digo até para você exatamente o que estava escrito - e o Roberto DaMatta estava na banca, provavelmente foi ele que inventou esse tema: "descreva um jogo de futebol como se você fosse uma pessoa de outra sociedade" (2013:4).

Além de DaMatta, a banca era composta por Lygia Sigaud (19452009), formada na Sociologia da PUC-Rio e então muito jovem, e por Francisca Isabel Schurig Vieira Keller (1935-1981), professora cujo nome é homenageado hoje pela biblioteca da instituição. Chiquita, como era carinhosamente conhecida por Simoni, foi da primeira turma de professores convidados por Roberto Cardoso de Oliveira para compor o corpo docente da instituição. Formara-se em Geografia e História na PUC-SP, em 1957, e tornara-se mestre em Antropologia Social no King's College da Universidade de Durham, na Inglaterra, em 1962. Em seguida, doutorara-se também em Antropologia pela FFLCH/USP, sob orientação de Florestan Fernandes, no ano de 1967.

O programa de mestrado em Antropologia Social do Museu Nacional foi o primeiro a ser criado no Rio de Janeiro, em 1968. Quando Simoni ingressou no mestrado do PPGAS havia poucas teses defendidas, mesmo havendo uma primeira versão de pós-graduação desde 1960. O tempo de confecção das teses era muito maior que nos dias atuais. A "tese" de mestrado de Simoni durou, por exemplo, cinco anos para ser concluída, mas havia situações em que podia levar ainda mais tempo, seis ou até sete anos. A previsão média era de quatro anos, mas havia menos rigor nesse prazo e, apenas para cumprir as disciplinas obrigatórias, eram necessários dois anos de aulas. Simoni obteve o título de mestre com bolsa da Capes e licença integral de seu trabalho no ensino público estadual.

A expansão dos cursos de pós-graduação no Brasil foi fruto da Reforma Universitária de 1968 a que aludimos acima. Para a sua implementação, os programas contaram com o apoio da agência de fomento estadunidense Fundação Ford. A Ford Foundation também auxiliou na criação do Instituto Universitário de Pesquisas do Rio de Janeiro (Iuperj), no Rio, em 1969, o Departamento de Ciência Política da UFMG, em Belo Horizonte, em 1966, e o Centro Brasileiro de Análise e Planejamento (Cebrap), em São Paulo, no ano de 1969.

À época, em nível de doutorado, existiam apenas cursos na Universidade de São Paulo, na sua Faculdade de Filosofia. O PPGAS criaria o seu doutorado no final dos anos 1970 e muitos de seus professores de História e Ciências Sociais do Rio, como Gilberto Velho (1945-2012), recorreriam à USP para 
se doutorar nos idos de 1970. No âmbito específico da Antropologia, depois do mestrado do Museu Nacional (1968), o da USP foi reestruturado em 1970, enquanto os da Unicamp e da UnB foram instituídos em 1971 e 1972, respectivamente.

Ainda em relação à história institucional e à ambiência repressiva da ditadura militar, recorremos ao pesquisador Leonardo Nóbrega Silva para a devida contextualização dos anos 1970 e para o destaque à especificidade do Museu Nacional nesse momento:

É de se notar que mesmo no período de repressão, o Museu Nacional esteve parcialmente protegido das incursões militares por conta do prestígio que a instituição acumulava e por suas pesquisas serem mais reconhecidamente relacionadas às ciências biológica, botânica, zoologia e arqueologia, restando a instituições como o IFCS, no Rio de Janeiro, uma maior vigilância por parte do regime em relação à atuação dos seus professores, pesquisadores e alunos (Silva 2019:200).

Dois antropólogos brasileiros, formados academicamente nos Estados Unidos, foram referenciais para a configuração do perfil do PPGAS nos anos 1970, aqui já mencionados: Roberto DaMatta e Gilberto Velho. Sendo a Antropologia uma área muito marcada no Brasil pela temática indígena, com a qual inclusive o DaMatta trabalhou em sua fase inicial, os dois autores foram de grande importância para a transição do campo antropológico rumo aos estudos urbanos ao longo daquele decênio (DaMatta 1973; Velho 1998).

É certo que, além da questão indígena, o tema do campesinato e do Brasil rural era igualmente muito forte na agenda de pesquisas do Museu. DaMatta e Velho investiram na formação de uma primeira geração de pesquisadores voltada às populações urbanas e aos grupos sociais estabelecidos nas grandes cidades. Simoni inscreve-se nessa primeira leva de aprendizes de antropólogos do "fenômeno urbano"3 na "selva das cidades", para falar como Brecht. Simoni menciona, por exemplo, que em 1973 realizou uma etnografia da "pelada" entre garotos de classe média em Niterói para a cadeira de Antropologia Urbana, ministrada por Gilberto Velho

A emergência dessa área era reflexo igualmente do célere processo de urbanização e de industrialização por que passava o país desde os anos 1950 e cujas marcas faziam-se cada vez mais fortes na sociedade brasileira do último quartel do século XX. A antropologia não poderia ficar imune à realidade circundante do Brasil de então.

Depois de defender mestrado no Museu em 1970, e de regressar da Universidade do Texas, em Austin, onde finaliza sua especialização em 1971, Gilberto Velho publica pela editora Zahar sua dissertação A utopia urbana 
(1973), um marco na literatura sobre o assunto. Em seu retorno, Velho divulga os autores da Escola de Chicago e do interacionismo simbólico, notadamente de antropólogos norte-americanos como Erving Goffman e Howard Becker, este último um futuro parceiro intelectual.

Conforme dito acima, Simoni é aluna de Gilberto nas aulas de mestrado do Museu. Ele a convida para a sua primeira publicação de um capítulo autoral. Trata-se da coletânea de 1974, Desvio e divergência: uma crítica de patologia social, que assistiria a reedições ao longo das décadas. A partir de trabalhos etnográficos da turma, Simoni redige o texto "Umbanda e loucura", fruto de sua incursão a campo, capaz de mostrar seu interesse pelas manifestações populares. Este dado se aprofundaria ao longo da vida, com etnografias de cultura urbana junto às classes trabalhadoras e às suas práticas corporais.

Pari passu à influência de DaMatta e de Velho, Simoni é aluna de Neuma Aguiar, Alcida Ramos e Lygia Sigaud. Vai procurar seu ex-professor de graduação da UFF, Luís de Castro Faria, um respeitado antropólogo, fundador da Associação Brasileira de Antropologia em 1955 e pesquisador que participara da Expedição à Serra do Norte em 1938, chefiada por Claude Lévi-Strauss, quando de sua visita ao Brasil. Escolhe-o para a orientação no mestrado. Segundo recordação da própria Simoni, Castro Faria detestava futebol, mas acolheu a novidade do assunto por considerá-lo relevante para a sociedade brasileira.

A tese de mestrado é afinal defendida em 1977, após um trabalho de campo de quase um ano de duração. A banca foi composta, além do orientador, pela arguidora Francisca Keller, que também estivera em sua seleção de ingresso no mestrado, orientadora de colegas como Neide Esterci e Maria Júlia Goldwasser, cuja dissertação faz uma etnografia da Escola de Samba Estação Primeira de Mangueira em meados daquele decênio. O outro arguidor da banca era Gilberto Velho, seu influente professor. Era uma época em que não existia a figura do suplente nas defesas.

O título minimalista de $O$ futebol brasileiro - instituição zero sugere uma espécie de trocadilho com o referencial teórico do estruturalismo, em especial com Lévi-Strauss. Se havia instituições políticas, nomeadas como primeiro poder (Executivo), segundo (Legislativo) e terceiro (Judiciário), o futebol equivalia, informalmente, pela sua importância na sociedade brasileiro, a uma instituição. Era um fenômeno institucional prévio àquelas e, por conseguinte, foi cunhado por Simoni de "instituição zero".

O mote do título dá corpo a um estudo original e pioneiro na história dos estudos futebolísticos brasileiros em nível de pós-graduação. Com dicção de época, Simoni elege a identidade nacional brasileira - temática 
retomada e aprofundada a partir dos anos 1990 pela autora, inclusive na chave comparativa com a Argentina e com outras práticas esportivas - nas Copas de 1950 e 1970.

Mas a abordagem da autora não se cinge apenas à construção discursiva da imprensa sobre os significados da derrota e da vitória - o levamento de material jornalístico é feito na Biblioteca Nacional -, o que depois se tornaria quase uma banalidade reiterada no trabalho de muitos pesquisadores. A grande contribuição aportada pelo mestrado é contemplada na segunda parte e diz respeito à relação dos operários fabris - objeto de sua tese nos anos 1980/1990 - com o tempo livre e com o futebol amador, por meio de uma pesquisa de campo no bairro suburbano de Bangu.

Se a tese defendida em 1977 não chega a ser publicada, é essa segunda parte do trabalho dissertativo que servirá de base para o capítulo "Subúrbio, celeiro de craques", lançado no livro germinal de DaMatta, Universo do futebol, 1982. É dele que iremos tratar na terceira e última partes deste artigo.

Antes de entrar na próxima seção, saliente-se ainda que, depois da defesa do mestrado, Simoni ficaria quase uma década afastada da pósgraduação. Aqui também vale ressaltar que, ao contrário dos dias de hoje, a vida acadêmica não dependia do título de doutor. O doutorado, ainda uma novidade na vida universitária brasileira, levava o pesquisador para fora do país ou realizava-se em paralelo às atividades regulares de pesquisa e ensino. Em alguns casos, nesse período, podia-se passar mais de dez anos em um processo de doutoramento no país.

Uma vez com o título de mestre, Simoni continua a dedicar-se à docência entre os anos 1970 e 1980. Conforme já mencionado, leciona em escolas públicas estaduais de Niterói, na faculdade particular de Filosofia Santa Doroteia, em Friburgo, e na UFF, onde começa a colaborar como docente justamente naquele ano de 1977.

É só em 1986, portanto, quase uma década depois do mestrado, que ela ingressa no doutorado no Museu Nacional. Desta feita, não mais sob orientação de Castro Faria, já ausente da instituição, mas de Luís Fernando Dias Duarte, tendo sido a primeira orientanda de doutorado deste professor. A temática escolhida era distinta do futebol no mestrado - para o título de doutor a pesquisa focaliza trabalhadores urbanos e sua lida na fábrica ${ }^{4}$-, a que volta a se dedicar depois de concluído o doutorado, em 1992, com uma agenda de pesquisa que se prolongaria por mais duas décadas.

Entrementes, o intervalo na pós-graduação, entre o mestrado e o doutorado, não significa que tenha se afastado do Museu Nacional. Em certo sentido, sem que o soubesse ou quisesse, pode-se dizer que uma "constelação do futebol" se organizou no Museu: quatro anos depois dela, outro mestre 
do PPGAS dedica-se à temática futebolística. Em 1981, Ricardo Benzaquen de Araújo, formado em História na PUC-Rio, e futuramente um dos mais eruditos intelectuais da área de Pensamento Social, importante subárea da Anpocs, defende a dissertação "Os gênios da pelota: um estudo do futebol como profissão".

Com orientação de Gilberto Velho, a pesquisa de Ricardo compreende trabalho de campo em dois clubes do Rio: um de porte grande, o Clube de Regatas do Flamengo, da zona sul do Rio, e então em fase de ouro em meio à geração de Zico e à conquista de títulos nacionais e internacionais; e outro clube de escala média, o tijucano e tradicional América Football Club. A dissertação opera com uma refinada análise simmeliana e maussiana das categorias de aprendizagem, talento e dom, colhidas na observação participante. É uma dissertação curta, com menos de 100 páginas, algo atípico para as extensões do mestrado de então, mas o resultado é brilhante e, assim como a tese de Simoni, nunca veio a público em livro.

Além de Benzaquen, nos anais do Boletim do Museu Nacional, em seu número 33, de 1979, consta um ensaio de autoria de Luiz Eduardo Soares, intitulado "Futebol e teatro: notas para uma análise de estratégias simbólicas". Trata-se de uma instigante leitura do rito de entrada em campo das equipes de futebol e de uma série de observações de bastidor dos preparativos dos atletas nos vestiários, a mobilizar um paralelismo dramatúrgico à la Goffman. Luiz Eduardo, assim como o amigo Ricardo, era outro egresso da graduação da PUC-Rio dos anos 1970, só que da área de Letras, e também se aproximava da Antropologia Social naquele momento, com uma pesquisa de campo sobre campesinato, sob orientação de Moacir Palmeira.

Um grande fruto geracional do Museu, que se vinculará ao temário do futebol e dos esportes, é José Sérgio Leite Lopes, hoje professor titular da instituição. No período, José Sérgio filiava-se ao grupo de pesquisa voltada aos estudos rurais e migratórios do Nordeste brasileiro, liderado por Palmeira. José Sérgio, contemporâneo de mestrado de Simoni, formado em Economia na PUC-Rio - com vivência na França em função do exílio a que seu pai, o físico Leite Lopes, foi submetido - defendera tese no Museu em 1975. Sua pesquisa, no entanto, já tematizava o operariado e a vida das classes trabalhadoras nas fábricas, uma afinidade eletiva com os interesses do universo fabril de Simoni.

Em 1983, enquanto desenvolve seu doutorado no Museu sob orientação de Lygia Sigaud, José Sérgio inicia um levantamento sobre a trajetória do jogador Garrincha, falecido naquele mesmo ano. Impactado pela repercussão de seu funeral e pelo modo como a mídia cobrira o enterro, dedica-se a 
reconstituir a etnografia da "morte da alegria do povo" e explora com perspicácia sua relação com as unidades industriais têxtis, no interior do estado do Rio de Janeiro. A pesquisa é publicada em 1989, em francês, na prestigiada revista Actes de la recherche en sciences sociales, após interlocução com Pierre Bourdieu e Roger Chartier, e em coautoria com Sylvain Maresca.

Simoni e José Sérgio são as duas "crias" do Museu Nacional que mais investiram no estudo das práticas esportivas a partir dos anos 1990. Em certo sentido, pode-se dizer que, numa resenha para a revista Mana, da própria instituição, foi Leite Lopes quem introduziu no Brasil a sociologia dos esportes desenvolvida por Norbert Elias e Eric Dunning na Inglaterra, a partir da publicação em francês, em princípios dos anos 1990, do livro Quest for excitement (1986).

Além disso, o artigo de José Sérgio sobre o jornalista esportivo Mário Filho, editado na Revista USP em 1994, seria uma publicação decisiva na constituição do campo de estudos do futebol, na medida em que a leitura do autor de O negro no futebol brasileiro suscitaria uma série de críticas, de debates teóricos e de problematizações metodológicas em torno da legitimidade no uso das fontes de pesquisa necessárias a uma história e a uma sociologia do tema racial no futebol e nos esportes do país.

\section{O subúrbio redivivo: do romantismo da cultura popular à etnografia da antropologia urbana}

Feitas as considerações constelares em torno da influência, direta ou indireta, da tese de Simoni na constituição desse subcampo de estudos no Museu Nacional, voltemos à conjuntura de fins dos anos 1970 e de início dos anos 1980. Nesse período, Simoni estreitou vínculos com Roberto DaMatta e com seus alunos, especialmente Arno Vogel e Luís Felipe Baêta Neves, que também se interessavam por futebol. A projeção alcançada por DaMatta nessa virada de decênio é decorrência do lançamento de Carnavais, malandros e heróis: para uma sociologia do dilema brasileiro (1979). Para uma escala acadêmica, pode-se aludir ao sucesso editorial do livro lançado pela Zahar, com reconhecimento que extrapolou os muros universitários.

A publicação projeta DaMatta como um intérprete da sociedade brasileira contemporânea. Chega-se a filiar a obra à melhor linhagem do ensaísmo social desde os anos 1930, na esteira das interpretações de Gilberto Freyre e de Sérgio Buarque. A esta dimensão identitária nacional, DaMatta agrega seu arrojado repertório acadêmico, oriundo da teoria antropológica e 
sociológica sorvida nos Estados Unidos, na França e na Inglaterra do século XX. Destaque-se em especial seu diálogo com a valoração moral weberiana das ações sociais, com o estruturalismo francês lévi-straussiano e com o estrutural-funcionalismo britânico, graças à mobilização da ascese religiosa em Weber, da communitas em Victor Turner e do individualismo em Louis Dumont para o entendimento dos códigos culturais brasileiros, quer sejam os hierárquicos, quer sejam os meritocráticos.

O êxito de Carnavais, malandros e heróis em fins dos anos 1970 tem desdobramentos imediatos e resulta em convites de outras editoras a DaMatta para a organização de novos livros com temáticas afins à cultura popular urbana. Com efeito, o antropólogo organiza Universo do carnaval (1980), uma cobertura textual e imagética de cenas do multicolorido ambiente carnavalesco carioca de princípios dos anos 1980, já em meio ao avançado processo institucional de reabertura política, que põe termo ao \ regime discricionário.

Os ventos democráticos impactam o cotidiano e os comportamentos da população e da própria Academia, como propõe Luiz Henrique de Toledo (2009) em sugestivo ensaio comparativo dos estilos de pensar entre DaMatta e o argentino Eduardo Archetti, outro autor decisivo da Simoni "madura". DaMatta flagra no livro a ainda maior licenciosidade e o erotismo do carnaval daquele período, em obra repleta de fotos ousadas, com corpos nus e seminus, nos bailes de clube e nos desfiles de rua.

A mesma editora Pinakotheke vai publicar, dois anos depois de Universo do carnaval outro livro marcante. A obra segue a mesma estrutura - capa dura, edição luxuosa, ilustrada e colorida -, e o mesmo propósito - revelar facetas da cultura popular da cidade do Rio -, desta feita intitulado Universo do futebol (1982). A coletânea vem adornada de uma pequena pinacoteca: são 25 telas de pintores brasileiros - do quilate de Ismael Nery, Rebolo, Portinari, Djanira e Rubens Gerchman. Suas feições artísticas coexistem com um conteúdo antropológico acadêmico, compromissado com a linguagem científica da época.

O "time" de DaMatta conta com três ex-alunos, formados ou em formação, no Museu Nacional. A abertura traz um texto ensaístico da lavra do próprio DaMatta: "Esporte na sociedade - um ensaio social sobre o futebol brasileiro", cujo propósito é desconstruir a velha máxima, que recrudescera após a Copa de 1970, de que este esporte era o "ópio do povo".

O texto é seguido do capítulo de autoria de Luiz Felipe Baêta Neves, então professor da Fundação Getúlio Vargas e do próprio Museu Nacional. Quatro anos mais velho que Simoni, Baêta Neves já se encontrava no doutorado, com um estudo sobre a história da imaginação social jesuítica, 
tese concluída em 1984, sob orientação de Castro Faria. Ainda que estudasse outro assunto em sua linha principal de pesquisa, Baêta Neves produz o instigante trabalho de final de curso da disciplina de DaMatta: "Na zona do agrião: algumas mensagens ideológicas do futebol".

Simoni, por sua vez, comparece com o terceiro texto, um extrato retrabalhado de sua tese de mestrado, defendida cinco anos antes. O título do capítulo é simples, mas sugestivo: "Subúrbio: celeiro de craques" e sobre ele trataremos neste último tópico do capítulo.

Por fim, o quarto e último texto é do catarinense Arno Vogel, então colega de Simoni no Departamento de Ciências Sociais na UFF, e que defenderia seu mestrado no Museu naquele ano de 1982, orientado por DaMatta, com uma etnografia sobre a vinda do Papa João Paulo II ao Brasil, em 1980. Vogel assina o alentado e cativante: "O momento feliz: reflexões sobre o futebol e o ethos nacional". O título do texto de Arno alude a um poema de Carlos Drummond de Andrade e sua abordagem volta-se para a comparação do "luto" da Copa de 1950 com a "glória" redentora do Mundial de 1970.

Em entrevista ao portal Ludopédio, Simoni confessa que, na divisão do livro proposta por DaMatta, gostaria de ter ficado com este último tema, que fora objeto da primeira parte de sua dissertação. De todo modo, a contribuição de Simoni ao livro acaba por se revelar ímpar no conjunto da obra. Enquanto seus colegas seguem pela via do ensaio, baseados nas fontes secundárias da imprensa e do jornalismo esportivo, é Simoni quem efetivamente comparece na coletânea com uma etnografia estrito senso.

Pablo Alabarces, em palestra no III Encontro Internacional sobre Futebol Feminino na América Latina, em abril de 2019, nota o ponto com acuidade e salienta este diferencial da antropóloga vis-à-vis dos demais colaboradores. Simoni é, aliás, a única mulher a comparecer na obra, uma diferença de gênero que não pode ser olvidada e para a qual Luís Fernando Rojo chama a atenção em artigo sobre a importância da autora para a antropologia das práticas esportivas na América Latina (2019:273).

O capítulo de Simoni é uma pequena obra-prima, um microcosmo dos interesses da autora ao longo da sua carreira acadêmica. Vamos a seguir nos deter na morfologia que emoldura o texto. Em primeiro lugar, observe-se um detalhe no título: seu tema não é, a princípio, o futebol, mas um território, um espaço social, uma geografia, associada por sua vez ao espaço metropolitano do Rio de Janeiro e ao imaginário fulcral da sua formação histórica: o subúrbio.

Junto ao título, salta à vista o conciso e metafórico subtítulo: "celeiro de craques". Celeiro, segundo os dicionários, designa um espaço rural de produção agrícola onde se armazenam grãos, fruto das colheitas. 
O artigo, pois, coloca no horizonte a metáfora de uma região afastada do centro urbano, por conseguinte, mais próxima do ambiente rural e/ ou comunitário. Nele reúnem-se os "craques", isto é, os futebolistas extraordinários. Não se trata, pois, apenas de uma metáfora, mas de uma analogia advinda da agricultura, o que remete à exportação, à economia e à fonte de riqueza nacional, modo estruturante do país desde os tempos coloniais, ou seja, os futebolistas são nosso principal produto exportador, aquilo que mais à frente se chamará de "pés-de-obra" ou, na atualização do jargão, numa commodity futebolística.

Está posto, portanto, um tema que Simoni perseguiria na sua agenda de estudos futebolísticos: a técnica corporal contida na figura do talentoso jogador de futebol. Ou por outra: o trajeto do personagem obscuro que advém das camadas baixas e das zonas periféricas pobres - a favela de Jacarezinho, no caso do "malandro" e "salvador" Romário, ou o bairro de Jardim Irene, no caso de Cafu, futebolista, capitão da Seleção, cujo gesto na Copa de 2002 sempre a cativou - para adquirir o estrelato.

Seu foco mira a mobilidade do jogador que ascende socialmente graças à visibilidade outorgada pelo selecionado nacional ou pelos grandes clubes das principais cidades brasileiras, e analisa os modos pelos quais ele se vale para se manter na nova posição ou estrato social.

Enquanto esse assunto será tratado pelo senso comum de forma bastante chã, quando não estereotipada, Simoni levará a sério a complexidade simbólico-social do tema. A autora se mostrará sempre interessada em observar a articulação entre a proveniência social dos atletas oriundos de meios desfavorecidos e a projeção pública de suas respectivas imagens no esporte de alto rendimento. O olhar treinado da antropóloga interroga a conversão do habitus, a internalização de novo etos comportamental, em face dos constrangimentos morais e dos valores exigidos pela opinião pública e pelo meio futebolístico. Uma galeria de jogadores poderia ser aqui evocada e um dos últimos a que Simoni se dedicou nos anos 2010 foi Neymar Junior.

"Subúrbio, celeiro de craques" ainda não se ocupa da fama e dos destinos desses jogadores. O compromisso com a regra de ouro da antropologia, que é a imersão em campo e o contato direto e interpessoal com seus informantes, é cumprido à risca nessa sua iniciação à observação participante. A etnografia data de sua tese de mestrado, junto à fábrica Bangu, unidade industrial suburbana, icônica à época. Durante um ano inteiro, a jovem Simoni cumpriu seu trabalho de campo, entre 1975 e 1976, com então 26 anos de idade. Contou mais de uma vez quão longo era o périplo entre sua residência em Niterói e o distante bairro de Bangu, na periferia da cidade do Rio. 
A questão de gênero foi sempre uma curiosidade em relação a seu desempenho etnográfico. A pergunta em torno de como os nativos reagiram à presença de uma mulher em um ambiente de sociabilidade marcadamente masculino talvez tenha sido a pergunta que mais a interpelou entre os pares. Junto a ela, via de regra, prevaleceu a incredulidade quanto ao êxito em lograr uma inserção satisfatória. Talvez como uma estratégica de desconstrução da expectativa em torno de sua resposta, Simoni costumava dizer que, ao contrário, sua condição feminina favoreceu sua entrada em campo, no sentido de ter criado um diferencial mais facilitador que inviabilizador do acesso.

De volta ao arcabouço do capítulo em exame, pode-se afirmar que este é à primeira vista curto em termos de extensão, com apenas 15 páginas. Inicia-se na 59 e vai até a 74. Mas o tamanho aparentemente pequeno é um ledo engano, pois o acabamento artístico do livro, em formato coffee table book, dispõe de uma diagramação que duplica as laudas por página. O texto tem, logo, o dobro do que contabiliza, sendo em realidade de 30 páginas.

A estrutura do artigo também causa espécie: são cinco subdivisões internas principais, seguidas de uma conclusão. A entrada do texto soa metodológica: "Qualificação dos entrevistados". O tópico seguinte sinaliza para o argumento a ser desenvolvido: "Uma carreira frustrada". O encadeamento dos três últimos subitens sugere uma sequência narrativa bem urdida, a escandir "três fases": o sonho (primeira); a luta (segunda); a brincadeira (terceira).

Simoni embasa seu texto com os referenciais teóricos clássicos e contemporâneos da época, a exemplo de Marcel Mauss, Victor Turner, Marshall Sahlins e Howard Becker. Chama a atenção que, já nesse momento, entre a segunda metade dos anos 1970 e o início de 1980, mencione a obra de Pierre Bourdieu, cuja voga ainda não chegara com toda a força no país. A revisão da literatura sobre as unidades fabris no Rio de Janeiro leva Simoni ao trabalho da socióloga Vera Maria Pereira: O coração da fábrica: estudo de caso entre operários têxteis (1970).

Depois de tratar do futebol como significado sociocultural complexo e abrangente, Simoni circunscreve seu universo de informantes, todos eles operários de uma fábrica têxtil, com os quais trava contato graças à ajuda da pesquisadora Vera Pereira, na sede do Sindicato dos Trabalhadores na Indústria de Fiação e Tecelagem. Em seguida, "qualifica" o interesse pela história de vida de seus oito nativos do trabalho de campo, nomeando-os abstratamente por letras alfabéticas de A a H. A seleção dos atores tem em vista sua trajetória no futebol e aquilo que Simoni chama de "carreiras frustradas", porquanto seus objetivos finais não chegam a ser alcançados. 
Como dito, o sequenciamento dessa "carreira" é estruturado por Simoni em três momentos. O primeiro é "o sonho", dimensão associada à infância, à pelada e à projeção de uma meta a ser atingida na vida adulta. Tal dimensão onírica não é cultivada de maneira isolada, mas partilhada em família, com especial destaque para a figura paterna, também aficionado por futebol, ele mesmo um dia aspirante a jogador. O sonho diz respeito à ascensão social por intermédio da prática, que de lúdica se torna séria, dicotomia à época aceita sem maiores problemas, no bojo de uma embrionária sociologia do lazer. Em princípio, este fim será atingido quando se chegar à primeira divisão de um clube grande do futebol profissional.

Essa fase manifesta as "contingências de carreira", com a intercorrência de fatores como a chance, a sorte e o apoio, que determinam as vicissitudes do êxito futebolístico de inserção no círculo restrito desse mundo. Tal inserção depende de treinos e de testes sucessivos em clubes, do apoio familiar, da compreensão dos donos da fábrica, mas também de uma rede de relações influente, que pode facilitar ou dificultar sua entrada nas categorias juvenis.

Sem monopolizar a primeira pessoa do relato etnográfico, Simoni incorpora ao texto o ponto de vista dos observados, transcreve falas, salienta as categorias nativas do grupo de pessoas e compartilha sua visão de mundo. É assim que o mote "celeiro de craques", examinado acima, não se configura uma expressão atribuída pela autora, mas um próprio dado revelado na voz de um dos seus informantes.

A segunda fase estruturante intitula-se "a luta". Esta envolve o processo de profissionalização e as etapas verticais esperadas na ascensão rumo ao clube grande e à primeira divisão. Tal período é vivenciado quando se tem cerca de 20 anos de idade e o jogador já se encontra na fase profissional da carreira, quando se torna mais difícil a compatibilização entre a prática futebolística e o regime de trabalho operário. A condição interfere no modo de organização da rotina, bem como na tradicional demarcação entre os dias de semana - ordinariamente voltados ao trabalho - e os finais de semana via de regra, sinônimo de descanso, fruição, lazer.

Essa fase intermediária no processo social é marcada pela transição entre as "peladas" locais e a participação no campeonato da segunda divisão, o máximo alcançado pelo escopo de atletas observado por Simoni. Muitas vezes, não chega a haver uma transição completa entre uma fase e outra, mas a coexistência entre ambas, uma vez que a presença no futebol profissional empresta prestígio em nível comunitário, que o mantém no nível primeiro do "sonho".

Ademais, segundo sua observação, nos discursos colhidos, não raro se verifica uma inversão de status, com a valorização do amadorismo, em que 
se joga por "amor à camisa", em detrimento do profissionalismo, visto como descaracterizador da essência do jogo, em que o dinheiro instaura relações perversas e corrompe seu sentido original.

A pesquisa de campo traz o dado de que essa segunda fase encerra-se por volta dos 30 anos, quando, sem mais expectativas de subida na hierarquia do futebol profissional, o jogador-operário desconstrói sua condição de atleta para tornar a ver-se exclusivamente como trabalhador de fábrica. Entra em cena, doravante, a terceira fase: a "brincadeira". Ao sonho e à luta, sucede a volta ao terreno lúdico, isto é, ao reencontro do indivíduo com seu tempo de lazer, num momento em que sua vida precisa "assentar".

Trata-se, segundo Simoni, de um modo de se referir à faixa etária e ao estado físico, o que implica um distinto tipo de relacionamento com a vivência do futebol, novamente integrada à esfera de pertencimento comunitário e ao seio vicinal de origem. As festividades locais sugerem a ambiência propícia às fofocas (a autora ainda não conhece o Norbert Elias de Os estabelecidos e os outsiders), ao falatório e às relações jocosas, que se relacionam a um tema que interessará Simoni numa de suas agendas de pesquisa: o envelhecimento (Simoni também ainda não conhece o Elias de A solidão dos moribundos, publicado em inglês naquele ano de 1982).

No caso do universo pesquisado, a antropóloga identifica a expressão nativa "cacareco", que suscita os risos de uma sociabilidade includente e jocosa. A autora fisga o ponto certo: o jogador "velho" concerne a uma dimensão relativizável em função de certa precocidade do fim da carreira, pois, em termos biológico-contábeis, o jogador encontra-se tão somente no fim da sua juventude e no início da sua vida madura.

Simoni mostra-se atenta às sutilezas do sistema classificatório com que opera e sublinha que a fase da "brincadeira" entre os adultos é distinta do jogo de bola lúdico da infância. A "pelada" entre os operários mais velhos, praticada nas praças e nos terrenos baldios do bairro, é levada a sério por seus praticantes, cuja carreira previamente traçada cunha diferentes gradações de status e reputação, internos às relações vicinais.

Sob esse aspecto, não só os jogadores têm prestígio, mas igualmente os times que representam e que disputam competições. Estas por seu turno demandam outro tipo de investimento no relacionamento dos subgrupos: a posse de material esportivo. Deste, uma indumentária crucial é o calçado, figurando um modo de diferenciação entre os que jogam descalços e os que usam tênis ou chuteira no campo de terra batida. Outro item imprescindível são as camisas, com a demarcação das equipes capazes de padronizar um uniforme entre os seus integrantes e aqueles que não conseguem recursos econômicos nem organização suficiente para fazê-lo. 
O último momento etnográfico a observar, no fecho do capítulo, é o momento consecutivo à partida. Ao invés da dispersão, assiste-se à confraternização. Eis aqui o que Simoni chama posteriormente de "terceiro tempo", reconhecendo o momento mais difícil para ela, na condição feminina e/ou forasteira, de participar. Nela, daquilo que logra observar, os laços sociais, em função da vitória ou da derrota, podem se soldar ou se mitigar. O locus para esse encontro festivo é a mesa de bar nas redondezas do campo. Valoriza-se nesse momento especialmente o consumo de cerveja, que animará as conversas e as rememorações narradas em torno das cenas e dos lances do jogo.

\section{À guisa de conclusão}

Diante do exposto, eis a homenagem que gostaríamos de oferecer a essa intelectual. De Simoni, guardamos vivo na lembrança o que aprendemos nas reuniões do Nepess/UFF, nos fóruns científicos, nas bancas de mestrado e doutorado, nos bares, nos estádios e em tantos outros espaços de convívio. Sua obra e sua postura intelectual - lado a lado com seu jeito franco, carismático e autêntico - são exemplo, por tudo que legou à formação de discentes, docentes e pesquisadores, do que construiu para a autonomização da Antropologia dos Esportes e para a afirmação das Ciências Sociais no Brasil.

Como foi possível observar acima, ao contrário da norma científica, este artigo evocativo não conseguiu utilizar o sobrenome Guedes para referir ao objeto de nosso texto. Foi forçoso evocá-la por seu primeiro nome, como todos a chamavam no dia a dia das aulas e dos encontros acadêmicos.

Simoni fica na memória afetiva das gerações que a conheceram pessoalmente. Seus artigos, capítulos e livros inspirarão os jovens que ainda vão chegar à universidade. Estes hão de se valer de tudo aquilo que refletiu e produziu sobre a antropologia das práticas esportivas e sobre o imaginário do futebol brasileiro, instituição zero.

Recebido em 17 de julho de 2020

Aprovado em 06 de março de 2021 
Bernardo Borges Buarque de Hollanda é Doutor em História Social da Cultura (PUC-Rio-2008), com pós-doutorado na Maison des sciences de l'homme (Bourse Hermès-2009), na University of Birmingham (Rutherford Fellowship-2018) e no Centre international d'étude du sport (Neuchâtel-2020). Pesquisador do CNPq.

https://orcid.org/0000-0001-7781-4684

E-mail: Bernardo.Hollanda@fgv.br

\section{Agradecimentos}

Este artigo não seria possível sem a generosa colaboração de Mylene Guedes, filha de Simoni, e de Anamaria das Graças Souza Wagner, uma das melhores amigas da autora, sua contemporânea de graduação em Ciências Sociais na UFF, entre 1968 e 1973. Agradecemos também a Pedro Pio, orientando de Simoni no mestrado, pela ajuda nas informações, e ao professor Jimmy Medeiros (Escola de Ciências Sociais/FGV-CPDOC), pela mediação nos contatos. Um agradecimento a Luiz Henrique de Toledo (Prof. titular/ UFSCar) e a Isabela Trindade Menezes (Profa./IFRJ) pelas interlocuções profícuas ao longo da confecção deste texto. Agradeço aos amigos Marcos Alvito e Luiz Burlamaqui pelas leituras atentas, pelas correções precisas e pelas instigantes sugestões para a melhoria do artigo. Um agradecimento final é necessário aos pareceristas anônimos, cujas críticas e sugestões contribuíram para o aprimoramento do texto em sua versão final.

\section{Notas}

1 Para maiores informações, acessar: https://www.historia.uff.br/nepess/ apresentacao.html

2 Em contrapartida a certa visão mais benevolente em relação à liberdade que grassava no campus da UFF, pesquisas contemporâneas procuram acentuar a forte repressão que a instituição universitária vivenciou no período (Cf. Pereira 2016).

3 Título de coletânea de 1967, organizada por Otávio Velho, irmão de Gilberto, pela Editora Zahar.

4 A tese é publicada em livro, sendo intitulada: Jogo de corpo - um estudo de construção social de trabalhadores. Niterói: EDUFF, 1997. 


\section{Referências bibliográficas}

ALMEIDA, Maria Hermínia Tavares de. 1998. "Carro zero e pau-de-arara: o cotidiano de oposição de classe média ao regime militar". In: Lilia Schwarcz (org.), História da vida privada no Brasil. Vol. 4. São Paulo: Companhia das Letras.

BOURDIEU, Pierre. 2006. "A ilusão biográfica". In: Janaína Amado \& Marieta de Moraes Ferreira, Usos e abusos da história oral. Rio de Janeiro: FGV Editora

CAMPOS, Mintaha Alcuri. 1987. Turco pobre, sírio remediado, libanês rico: a trajetória do imigrante libanês no Espírito Santo (1910-1940). Vitória: Instituto Jones Santos Neves.

CORTE, Andrea Tello da \& MARTINS, Ismênia de Lima (orgs.). 2010. 50 anos da Universidade Federal Fluminense (1960-2010). Niterói: EDUFF.

DaMATTA, Roberto. 1973. Ensaios de antropologia estrutural. Petrópolis: Vozes.

DAMO, Arlei. 2002. Futebol e identidades sociais: uma leitura antropológica da rivalidade entre torcedores e clubes. Porto Alegre: Ed. UFRGS.

GASTALDO, Édison. 2002. Futebol, chuteiras e propaganda: o brasileiro na publicidade da Copa do Mundo. São Paulo: Annablume.

GUEDES, Simoni Lahud. 1974. "Umbanda e loucura". In: Gilberto Velho (org.), Desvio e divergência: uma crítica de patologia social. Rio de Janeiro: Jorge Zahar. 1977. Futebol, instituição zero. Tese de Mestrado em Antropologia Social/ UFRJ.

. 1982. "Subúrbio, celeiro de craques". In: Roberto DaMatta (org.), Universo do futebol: esporte e sociedade brasileira. Rio de Janeiro: Edições Pinakotheke.

. 1997. Jogo de corpo: um estudo de construção social de trabalhadores. Niterói: Eduff.

2013. "Entrevista para o portal Ludopédio". Ludopédio, São Paulo, p. $1-20$

. 2017. "Sobre permanências e transformações em contextos acadêmico-institucionais: um relato pessoal". Revista Antropolítica, Niterói, n. 42, p. 339-373.

OLIVEIRA, Roberto Cardoso. 1998. O trabalho do antropólogo. Brasília: Paralelo 15.

MASCARENHAS, Gilmar. 2014 . Entradas e bandeiras: a conquista do Brasil pelo futebol. Rio de Janeiro: Ed. UERJ.

PEREIRA, Ludmila Gama. 2016. Nenhuma ilha da liberdade: vigilância, controle e repressão na Universidade Federal Fluminense (1964-1987). Tese de Doutorado em História/UFF.

RAMOS, Roberto. 1984. Futebol, ideologia do poder. Petrópolis: Vozes.

ROJO, Luiz Fernando. 2019. "Simoni Guedes: uma trajetória na antropologia dos esportes". Revista Antropolítica, Niterói, n. 46, p. 272 289.

SEBRELI, Juan José. 1998. La era del fútbol. Buenos Aires: Editorial Sudamericana.

SILVA, Leonardo Nóbrega da. 2019. Editoras e ciências sociais no Brasil: a Zahar Editores e a emergência das ciências sociais como um gênero editorial (1957-1984). Rio de Janeiro: UERJ/IESP. 
TOLEDO, Luiz Henrique de. 2009. "Estilos de jogar, estilos de pensar: esboço comparativo entre DaMatta e Archetti". In: Luiz Henrique de Toledo \& Carlos Eduardo Costa (orgs), Visão de campo: antropologia das práticas esportivas. São Paulo: Terceiro Nome.

\section{Palestra}

ALABARCES, Pablo. 2019. "El fútbol y el deporte como política: homenaje a Simoni". In: III Encontro Internacional sobre Futebol Feminino na América Latina. Rio de Janeiro: Fundação Getúlio Vargas.
VELHO, Gilberto. 1973. A utopia urbana: um estudo de ideologia e urbanização. Rio de Janeiro: Zahar. . 1998. Nobres e anjos: um estudo de tóxicos e hierarquia. Rio de Janeiro: FGV Editora.

VELHO, Otávio (org.). 1967. O fenômeno urbano. Rio de Janeiro: Zahar. 


\section{RETRATO DA ANTROPÓLOGA QUANDO JOVEM : SIMONI GUEDES - DOS ANOS DE FORMAÇÃO A SUBÚRBIO, CELEIRO DE CRAQUES}

\section{Resumo}

O presente artigo, escrito em homenagem à antropóloga Simoni Guedes (19492019), reconstitui elementos da trajetória de uma autora que exerceu notável influência na constituição de um campo de estudos para a antropologia dos esportes no Brasil. De início, o propósito do texto é dar a conhecer dados biográficos de suas origens familiares e de sua formação em Ciências Sociais na Universidade Federal Fluminense (UFF), entre os anos 1960 e 1970, informações via de regra pouco conhecidas, mesmo entre seus discípulos. Em seguida, aborda-se a importância de sua formação acadêmica no Programa de Pós-Graduação em Antropologia Social (PPGAS), do Museu Nacional, entre as décadas de 1970 e 1990, instituição em que se tornou mestra e doutora. Depois de traçar esse percurso intelectual formativo, tencionase por fim um exame mais detido em sua primeira publicação de vulto, dedicada à temática esportiva - "Subúrbio, celeiro de craques" -, que veio a lume em 1982, em coletânea germinal organizada por Roberto DaMatta: Universo do futebol. Palavras-chave: História das Ciências Sociais no Brasil; Antropologia do Esporte; Trajetória de Simoni Guedes.
PORTRAIT OF THE

ANTHROPOLOGIST AS A YOUNG

WOMAN: SIMONI GUEDES FROM HER FORM ATIVE YEARS TO

SUBÚRBIO, CELEIRO DE CRAQUES

\section{Abstract}

Written in honor of the anthropologist Simoni Guedes (1949-2019), this article reconstructs elements of the trajectory of an author who had a notable influence on the constitution of a field of research in the anthropology of sports in Brazil. First, this article makes known biographical data on her family origins and training in the Social Sciences at the Federal Fluminense University (UFF), in the 1960s and 1970s - information that is little known, even among her students. Second, I discuss the importance of her academic training at the Graduate Program in Social Anthropology (PPGAS) of the National Museum of Brazil, from the 1970s to the 1990s, an institution where she obtained her MPhil and Ph.D. After traversing this intellectual path, I take a closer look at her first major publications on sports - "Subúrbio, celeiro de craques" - which was first published in 1982, in Universo do futebol, a seminal volume edited by Roberto DaMatta.

Keywords: History of social sciences in Brazil; Anthropology of sport; Simoni Guedes' trajectory. 
RETRATO DE UMA ANTROPÓLOGA

JOVEN: SIMONI GUEDES, DE LOS

AÑOS DE FORMACIÓN A SUBÚRBIO,

\section{CELEIRO DE CRAQUES}

\section{Resumen}

Escrito en homenaje a la antropóloga Simoni Guedes (1949-2019), el presente artículo tiene como objetivo reconstruir la trayectoria de una autora que ejerció una notable influencia al constituir un campo de estudios para la antropología deportiva en Brasil. Inicialmente, el texto se propone exponer los datos biográficos acerca de los orígenes de su familia y su formación en Ciencias Sociales en la Universidad Federal Fluminense (UFF), entre los años 1960 y 1970, informaciones que son generalmente poco conocidas, incluso entre sus discípulos. Después, se aborda la importancia de su formación académica en el Programa de Posgrado en Antropología Social (PPGAS) del Museo Nacional, entre los años 1970 y 1990, una institución donde se recibió como magíster y doctora. Tras el establecimiento de esta trayectoria formativa intelectual, por último, se realiza un análisis más detallado de su primera publicación dedicada al tema deportivo -"Subúrbio, celeiro de craques"-, que se editó en 1982 en una colección seminal organizada por Roberto DaMatta llamada Universo do futebol.

Palabras claves: Historia de las ciencias sociales en Brasil; Antropología del deporte; Trayectoria de Simoni Guedes. 